\title{
If the shoe fits, choose it: Tailored strategy for postcoarctation complications
}

\author{
Eric E. Roselli, MD
}

\footnotetext{
From the Aorta Center, Department of Thoracic and Cardiovascular Surgery, Heart and Vascular Institute, Cleveland Clinic, Cleveland, Ohio.

Disclosures: Author has nothing to disclose with regard to commercial support.

Received for publication Feb 15, 2016; accepted for publication Feb 19, 2016; available ahead of print March 18, 2016.

Address for reprints: Eric E. Roselli, MD, Department of Thoracic and Cardiovascular Surgery, Cleveland Clinic, 9500 Euclid Ave, Desk J4-1 Cleveland, OH 44195-5108 (E-mail: roselle@ccf.org).

J Thorac Cardiovasc Surg 2016;151:1764-5

$0022-5223 / \$ 36.00$

Copyright (c) 2016 by The American Association for Thoracic Surgery

http://dx.doi.org/10.1016/j.jtcvs.2016.02.041
}

Despite improvements in survival due to early detection and better medicine, many late survivors after repair of aortic coarctation will develop complications, including recurrent coarctation, aneurysms, or pseudoaneurysms in the treated segment. ${ }^{1}$ In a review of 110 adolescents and adults undergoing open, hybrid, or endovascular repair at the Cleveland Clinic, we found the mean age at intervention was 38 years and most reoperations occurred more than 2 decades after initial repair. $^{2}$ These adults with congenital aortic disease require optimal medical therapy and lifelong surveillance with intermittent cross-sectional imaging to screen for late complications. When they reach a threshold where reintervention is indicated, they do well with repair when performed at a high-volume aortic center. Cabasa and colleagues $^{3}$ describe an excellent outcome in a 47-yearold patient after a third-time operation at their highvolume tertiary center, with experience caring for complex thoracic aortic disease, 36 years after his last operation.

The patient described in this well-done report and accompanying video developed a 6-cm pseudoaneurysm at the site of a previous aorta bypass. Indication to reoperate was undeniable given the large size and the patient's age. With pseudoaneurysm or saccular aneurysms after previous coarctation repair, I often recommend repair even sooner given their less predictable nature. Preoperative computed tomography demonstrated a lobulated shape consistent with the complex morphology of this disease.

It is not surprising to see that this patient developed this complication. The old graft looked rather small for a welldeveloped adult male and may have become scarred down over approximately 4 decades. Tissue that the bypass was sewn to was proximal on the descending aorta and probably not great quality. We have also seen late degeneration of these grafts over a long period of time and have even described aneurysm of a knitted graft used the same way: passing across the pulmonary trunk from ascending to descending. ${ }^{4}$ Nonetheless, use of aortic bypass is typically durable for treating coarctation. When doing so, we choose an 18- to 20-mm graft and prefer retrocaval positioning to the anterior

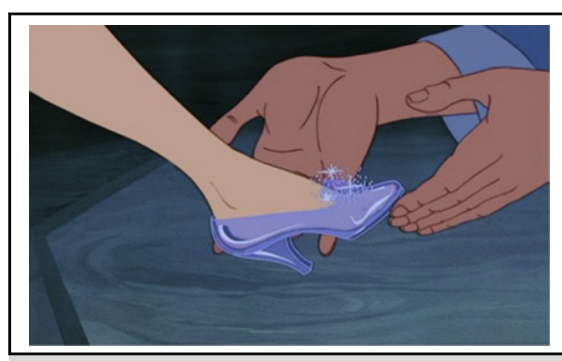

If the shoe fits, choose it.

Central Message

Safe treatment of late complications after coarctation repair requires tailoring open, hybrid, or endovascular techniques to the patient, considering comorbidities, anatomy, morphology, and experience.

See Article page 1760.

lie for performing this repair. Although very helpful for late or recurrent coarctation, bypass will not satisfactorily address aneurysm without additional intervention.

Several approaches, including endovascular and hybrid techniques, may be applied to these patients. ${ }^{2,5}$ Selecting the best approach for each patient requires careful consideration of several factors. First, we consider comorbid cardiovascular disease and the need for concomitant procedures. For example, if the patient has severe stenosis of a bicuspid aortic valve, then we choose an open or hybrid approach through a partial or full sternotomy that allows for cardiac arrest and valve replacement. This patient had normal cardiac and valvular function, and coronary angiography. Next, we consider morphology of the aneurysm itself and the condition of the arch disease. The length of aorta involved with aneurysm in this patient is short, and the descending aorta beyond the disease is normal appearing. This suggests that a single-stage repair will suffice, and a 2-stage elephant trunk procedure is not necessary.

Close inspection of the arch is required to determine the potential for a purely endovascular repair. This patient's coarctation was very proximal, involving the origin of the left subclavian and the left common carotid artery, leaving no adequate landing zone for a safe endovascular repair. A hybrid reconstruction involving partial sternotomy and direct device delivery through the coarctation with patch reconstruction of the hypoplastic segment would have been feasible and may have limited the need for distal 
exposure and manipulation of the recurrent laryngeal nerve, but it is still a rather invasive operation dependent on surgical experience with these techniques. ${ }^{5}$ Instead, the authors chose a trapdoor incision to resect all of the involved segments, perform an anatomic reconstruction using modern techniques for brain protection, and create a direct bypass to the left subclavian artery. This technique was more invasive and complicated by left recurrent laryngeal nerve palsy, but it was well tolerated, and the patient recovered well with what appears to be a very functional and, hopefully, durable anatomic result. They chose the shoe that fit, based on what they found, and are to be congratulated on a good result.

\section{References}

1. Brown ML, Burkhart HM, Connolly HM, Dearani JA, Hagler DJ, Schaff HV. Late outcomes of reintervention on the descending aorta after repair of aortic coarctation. Circulation. 2010;122(Suppl):81-4.

2. Roselli EE, Qureshi A, Idrees J, Lima B, Greenberg RK, Svensson LG, et al. Ann Thorac Surg. 2012;94:751-8.

3. Cabasa AS, Bower TC, Pochettino AB. Arch reconstruction after a previous ascending-to-descending aortic bypass for coarctation of the aorta. J Thorac Cardiovasc Surg. 2016;151:1760-3.

4. Kalahasti V, Roselli EE, Flamm SD, Krasuski RA. Aneurysmal ascending to descending aorta bypass graft compressing the pulmonary artery. Interact Cardiovasc Thorac Surg. 2009;9:730-2.

5. Idrees J, Roselli EE, Blackstone EH, Clair D, Svensson LG. Hybrid repair of aortic aneurysm in patients with previous coarctation. J Thorac Cardiovasc Surg. 2014; 148:60-4. 